\title{
Language Endangerment: An Overview of the Ethnolinguistic Vitality of Some Cameroonian Languages
}

\author{
Njwe nee Amah Eyovi Ntongieh \\ The University of Bamenda, Bambili, Cameroon
}

\begin{abstract}
The nation of Cameroon practices Exoglossic Bilingualism whereby, French and English are used as official languages instituted by the constitution of Cameroon. Alongside the official languages are about 284 minority languages with unequal vitality. The official languages together with a lingua franca Pidgin English and a few indigenous languages which have gained regional recognition exert great pressure on some of the indigenous minority languages, endangering them and leaving some almost at the verge of extinction if the situation is not reversed. Endeavours at assessing the language vitality situation reveal that Ngwo and Maykuyə (generally known as mankon) spoken in the North West, Nweh in the South West, and Ngomba in the West regions of Cameron face such pressure and are each relatively endangered. Various strategies worthwhile to overcome language endangerment have been considered.
\end{abstract}

Keywords: language endangerment, ethnolinguistic vitality, exoglossic, bilingualism, official languages, lingua franca

\section{Introduction}

Cameroon has been classified by Grimes (2000) as one of the most linguistically diversified countries of the world. With her 286 languages, she accounts for about $5 \%$ of the world languages though her population in relation to the rest of the world is minuscule, about $0.02 \%$ of the world's total. The extreme multilingual situation of the country has provided a great avenue for contact between different languages. These languages have unequal prestige and vitality. To facilitate inter-ethnic communication and a smooth functioning of the system, the Government of Cameroon instituted an exoglossic bilingual policy whereby French and English, languages of the formal colonial masters are utilized as official languages promulgated by the constitution of Cameroon. There is also the presence of a lingua franca Pidgin (The Cameroon Pidgin English) which developed as a contact language to solve the problems of inter-ethnic communication amongst people of diverse ethnic groups who have various reasons to coexist especially in urban centres and plantation agricultural villages.

Over the years, this English based Pidgin which began in the coastal regions of Cameroon following contact with the early British missionaries and explorers and later colonial masters spread into the hinterlands and many of the urban centres. It is creolized by some members of the community especially of the younger generation of the plantation villages in the coastal areas and townships of the South West and North West regions.

Njwe nee Amah Eyovi Ntongieh, lecturer, Ph.D., Department of English Modern Letters, The University of Bamenda. 
This Pidgin, together with the official languages exerts great pressure on many of the minority indigenous languages leaving many of them at the verge of extinction. Ngwo and Maykuyə (known as mankon which is the name of the users of the language) of the North West, Nweh of the South West, and Ngomba of the West face problems of pressure from high vitality languages and constitute genuine causes for concern, considering the irredeemable loss of cultural heritage, identity of a people, and stability associated with the extinction of a language.

Bitjaa Kody (2005) undertook a provisional measurement of 284 languages spoken in Cameroon excluding the official languages. His findings showed that the positive pole of viability had 19 languages while the negative pole comprised 265 languages. His study was just a provisional measurement. In this study, a detailed investigation and description of the four cited languages was undertaken, and for want of space, summaries of the findings are presented here. The goal of this kind of study is to motivate similar investigations on each of the indigenous minority languages which all have a general problem at varying degrees with marked peculiarities. A more adequate method to address the problems in a bid to reverse the situation will definitely require such an investigation (or study).

At this juncture, a presentation of the individual languages will be provided.

Ngwo is a Western Grassfield Bantu language (ALCAM, 1991) of the Widikum subgroup. It is spoken by the Ngwo people of the North West region of Cameroon. Ngwo village is located about $70 \mathrm{~km}$ South West of Bamenda, the regional headquarters of the North West Region. The village is enclave because of lack of an all year motor able road from Bamenda to the village. The population of Ngwo stands at 25,000 people (NCUDA, 2014) and estimates drawn from the 2013 election census show that only about 3,000 people representing $12 \%$ of the total population reside in the village. There is acute rural urban migration. Many of the quarters (neighborhood) have been abandoned as many people have moved away from the village. Upon arrival to some of the quarters of the village, there is the impression of a ghost town settlement.

The indigenes are found in the cities of Yaoundé and Douala, the townships of the North West especially Bamenda, the towns and agricultural villages of the South West Region. A good number are in the diaspora especially in the United States. It is relevant to indicate the settlement pattern of the people because it has a direct implication on the use of the language. It should be noted that it is only indigenes resident in the village who all speak the language, that is, adults and children alike. However, as pointed out by Landweer (2000) in Indicators of Ethnolinguistic Vitality (IEV) for Papua New Guinea (PNG), the concept of "urban" was redefined to include a population center. These population centers such as government stations, regional schools, and hospitals behave like cosmopolitan centers with the use of different languages. This is true of Ngwo because those centers exist in the village and utilize English, Pidgin English, and sometimes French as means of communication instead of Ngwo. Children always move out when they attain adulthood for brighter opportunities but the aged hardly return to the village upon retirement. It is also difficult for families to come home for visits because of the poor state of the roads.

Next is the presentation of Maykuyə spoken by the Mankon people of the North West region. According to ALCAM (1991), Maykuyə is a Western Grassfield Bantu language of the Ngemba subgroup. The indigenes of Mankon total about 200,000 people found in Cameroon and abroad.

The peculiarity of this language is in the fact that the village of Mankon where this language is spoken has been transformed to a huge cosmopolitan center following the growth and extension of Bamenda municipality, the North West regional headquarter. The villagers live with people from other ethnic groups of Cameroon and 
foreigners from other countries. The situation has led to the suppression of Mankuy for Pidgin English, English and sometimes French for interethnic communication since many of the indigenes especially the children do not find any need to speak it. There is the infiltration of pidgin and sometimes English in domains traditionally reserved for the indigenous languages in multilingual settings.

Most often, even those who try to speak the indigeneous language code mix and sometimes code switch in intragroup communication. This results to the adulteration and degeneration of the language.

The next language of study is Nweh. Nweh is an Eastern Grassfield Bantu of the Bamileke subgroup ALCAM (1991) spoken by the Ngwe people of the Lebialem Division of the South West region of Cameroon. Estimates by Atenchong (2012) put the population of the Ngwe people at about 113,721. They are found in Cameroon and abroad. Ngwe is peculiar in the sense that it is a transitional village between the Anglophones of the South West and the Franco phones in the West. The closest urban center to Ngwe is Dschang where the first official language is French.

Ngwe indigenes in Dschang speak Nweh in the environment of French, English, and Pidgin English.

Despite the multilingual nature of the speakers of Nweh, the indigenes uphold their cultural heritage and language. In the village, the parents speak the language to their children guaranteeing intergenerational transmission of Nweh. However, the language still faces pressure because of the status accorded the official languages and the lingua franca position of the Cameroon Pidgin English. There is also rural urban migration as well as the fact that, many non-indigenes resident in the village to carry out various governmental functions use mostly the official languages and Pidgin English.

From Ngwe, the next language to be described is Ngomba. Ngomba is an Eastern Grassfield Bantu language of the Bamileke sub group spoken in five villages of the Mbouda sub division of the west region of Cameroon. Ethnologue estimates its indigenes at 63,000 people. Some of these people live in the home land while others live in various parts of Cameroon especially in the major towns and cities and many others are found out of Cameroon. The first official language of the localities where Ngomba is spoken is French as opposed to English in the other languages described earlier. English is used in the localities but not mostly by indigenes. Another peculiarity is the fact that Cameroon Pidgin English is used but not as a lingua franca like in the former cases. From the population figure for indigenes of Ngomba users, one could quickly conclude that Ngomba is safe. However, report based on studies carried out on Bamendjida one of the five villages where Ngomba is spoken showed that the attitudes of the speakers toward Ngomba and language choice by the speakers do not favor maintenance. Parents speak Ngomba to their children ensuring intergenerational transmission. However, the presence of French constitutes a threat as language choice especially by the youngsters favor French as well as the attitude towards Ngomba compared to French favor the French language.

This study was undertaken by field observations, interviews and use of questionnaires. A number of trips were made to the various home lands where the four languages are spoken. During these trips, there were visits to the schools, churches, markets children's playground, as well as different ceremonial settings like funerals and births. There were also the opportunities to visit some homes. These movements were greatly facilitated by research students who hailed from the different villages. This provided the possibility to observe the use of language in the various settings, to view language choice in the different settings by the various speech participants. There was also the opportunity to carry out interviews with members of the various communities. In each of the four language communities investigated, 10 members were randomly selected comprising three 
men, three women, and four children. The questions asked ranged from the ability to use the indigenous languages fluently, instances of code mix and code switch, language preferences and reasons for various choices, language use with parents, children, peers, siblings, and the various domains and occasions. Attending the end of year village festivals of the four different speech communities under study of 2012 and 2013 provided a wonderful occasion to meet members in festivity settings. These festivals brought members from all over the country and abroad. This provided the opportunity to administer questionnaires to children and adult and all the various responses are the products of this ethnolinguistic vitality measurement presented in this study. To effectively measure ethnolinguistics vitality, there was the application of the United Nations Educational Scientific and Cultural Organization (UNESCO) frame work. To continue, there will be a description of the UNESCO frame work and presentation of summaries of findings from the different languages under investigation using the framework.

\section{Language Vitality Assessment: Major Evaluative Factors}

UNESCO ad hoc expert group on endangered languages (2003) presented a draft report entitled Language Vitality and Endangerment. This section gives a detailed discussion of the draft. It advanced nine criteria to be used in evaluating or assessing the state of endangerment of a language. Six criteria are used to evaluate the language vitality and state of endangerment and none of which should be used alone, two factors assess the language attitude and one evaluates the urgency of documentation. The nine criteria are follows: (1) intergenerational language transmission, (2) absolute number of speakers, (3) proportion of speakers within the total population, (4) shift in domains of use, (5) response to new domains and the media, (6) material for language education and literacy, (7) government and institutional language attitude and policy, (8) community members' attitude towards their own language, and (9) type and quality of documentation.

\section{Language Vitality and State of Endangerment Assessment}

Factor 1: Intergenerational transmission of the mother tongue. The most commonly used factor in evaluating the vitality of a language is whether or not it is being transmitted from one generation to the next (Fishman, 1991). This phenomenon has to do with the will of the parents to teach their language to their children. Actually, for a language to be perpetuated it has to be spoken by the children. Furthermore, the children have to learn the language in the traditional way (that is from their parents) and they have to learn it at home through hearing it from their parents. Endangerment can be ranked on a continuum from stability to extinction.

Six degrees to classify the degree of endangerment with regard to intergenerational transmission of the language can be distinguished, namely safe (5): The language is spoken by all generation. The intergenerational transmission of the language is uninterrupted.

Stable yet threatened (5-): The language is spoken in most contexts by all generation with unbroken intergenerational transmission, yet multilingualism in the native language and one or more dominant language(s) has usurped certain important communication contexts. Note that such multilingualism alone is not necessarily a threat to languages.

Unsafe (4): Most, but not all, children or families of particular community speak their parental language as their first language, but this may be restricted to specific social domains (such as the home where children interact with their parents and grandparents). 
Definitely endangered (3): The language is no longer being learned as the mother tongue by children in their home. The youngest speakers are those of the parental generation. At this stage, parents may still speak their language to their children, but their children do not typically respond in the language.

Severely endangered (2): The language is spoken only by grandparents and older generations; while the parent generation may still understand the language, they typically do not speak it to their children, or among themselves.

Critically endangered (1): The youngest speakers are in the great grand parental generation, and the language is not used for everyday interactions. These older people often remember only part of the language but do not use it on a regular basis, since there are few people left to speak with.

Table 1

Intergenerational Transmission of Language Description

\begin{tabular}{lll}
\hline Degree of endangerment Grade & Speaker population \\
\hline Safe & 5 & The language is used by all age groups, including children. \\
Unsafe & 4 & The language is used by some children in all domains; it is used by all children in limited domains. \\
Definitely endangered & 3 & The language is used mostly by the parental generation and upwards. \\
Severely endangered & 2 & The language is used mostly by the grand-parental generation and upwards. \\
Critically endangered & 1 & The language is known to very few speakers, of great-grandparental generation. \\
Extinct & 0 & There is no speaker left. \\
\hline
\end{tabular}

Factor 2: Absolute number of speakers. A small speech community is always at risk. A small population is much more vulnerable to decimation (by disease, warfare, or natural disaster, for example) than a larger one. A small language group may also easily merge with a neighboring group, giving up its own language and culture.

Factor 3: Proportion of speakers within the total population. The number of speakers of the ancestral language in relation to the total population of an ethnolinguistic group is a significant indicator of language vitality. The following scale can be used to appraise degrees of endangerment.

Table 2

Description of Proportion of Speakers Within the Total Population

\begin{tabular}{lll}
\hline Degree of endangerment & Grade & Proportion of speakers within the total reference population \\
\hline Safe & 5 & All speak the language. \\
Unsafe & 4 & Nearly all speak the language. \\
Definitely endangered & 3 & A majority speak the language. \\
Severely endangered & 2 & A minority speak the language. \\
Critically endangered & 1 & Very few speak the language. \\
Extinct & 0 & None speak the language. \\
\hline
\end{tabular}

Factor 4: Shifts in domains of language use. Where and with whom a language is used and the range of topics speakers can address by using the language has a direct effect on the transmission to the next generation. The following degrees of endangerment can be identified:

Universal use (5): The language of the ethnolinguistic group is actively used in all discourse domains for all purpose.

Multilingual parity (4): One or more dominant language, rather than the language of the ethnolinguistic group, is/are the primary language(s) in most official domains: government, public offices, and educational 
institutions. The language in question, however, may well continue to be integral to a number of public domains, especially in traditional religious institutions or practices, local stores, and places where members of the community socialize. The coexistence of the dominant and non-dominant languages results in speakers using each language for different functions (diglossia), whereby the non-dominant language is used in informal and home contexts and the dominant language is used in official and public contexts. Speakers may consider the dominant language to be the language of social and economic opportunity. However, older members of the community may continue to use only their ancestral language. Note that multilingualism, common throughout the world, does not necessarily lead to language loss.

Dwindling domains (3): The non-dominant language loses ground and, at home, parents begin to use the dominant language in their everyday interactions with their children; children become "semi-speakers" of their own language ("receptive bilinguals"). Parents and older members of the community tend to be productively bilingual in the dominant and the indigeneous language: They understand and speak both. Bilingual children may be found where the indigeneous language is actively used.

Limited or formal domains (2): The ancestral language may still be used at community centers as festivals and at ceremonial occasions where older members of the community have a chance to meet. The limited domains may also include homes where grandparents and other older extended family members reside. Many people can understand the language but cannot speak it.

Highly limited domains (1): The ancestral language is used in very restricted domains on special occasions, usually by very few individuals, for example, by ritual leaders on ceremonial occasions. Some other individuals may remember at least some of the language ("rememberers").

Extinct (0): The language is not spoken at any place at any time.

Table 3

Description of Domains and Functions of Language Use

\begin{tabular}{|c|c|c|}
\hline Degree of endangerment & Grade & Domain and function \\
\hline Universal use & 5 & The language is used in all domains and for all function. \\
\hline Multilingual parity & 4 & $\begin{array}{l}\text { Two or more languages may be used in most social domains and for most } \\
\text { functions; the ancestral language usually is rare in the public domain. }\end{array}$ \\
\hline Dwindling domain & 3 & $\begin{array}{l}\text { The ancestral language is used in home domains and for many functions, but the } \\
\text { dominant language begins to penetrate home domains. }\end{array}$ \\
\hline Limited or formal domains & 2 & The language is used in limited social domains and for several functions. \\
\hline Highly limited domains & 1 & The language is used only in very restricted domains and for a very few functions. \\
\hline Extinct & 0 & The language is not used in any domain at all. \\
\hline
\end{tabular}

Factor 5: Response to new domains and media. New areas for language use may emerge as community living conditions change. While some language communities do succeed in expanding their own language into the new domain, most do not. School, new work environments new media, including broadcast media and the Internet, usually serve only to expand the scope and power of dominant languages at the expense of all other languages. Although no existing domains of the endangered language may be lost, the use of the dominant language in the new domains has mesmerizing power, as with television. If the traditional language of a community does not meet the challenges of modernity, it becomes increasingly irrelevant and stigmatized. Degrees of endangerment in this respect are given in Table 4. 
Table 4

Description of Response to New Domains and Media

\begin{tabular}{lll}
\hline Degree of endangerment & Grade & New domains and media accepted by the endangered language \\
\hline Dynamic & 5 & The language is used in all new domains. \\
Robust/active & 4 & The language is used in most new domains. \\
Receptive & 3 & The language is used in many domains. \\
Coping & 2 & The language is used in some new domains. \\
Minimal & 1 & The language is used in only a few new domains. \\
Inactive & 0 & The language is not used in any new domains. \\
\hline
\end{tabular}

In education, assigning criteria can be based on two dimensions: Up to what level, and how broadly across the curriculum, the endangered language is used. An endangered language which is the medium of instruction for all course and at all levels will rank much higher than an endangered language that is taught for only one hour per week. All new domains, be they in employment, education, or the media, must be considered together when assessing an endangered language community's response.

Factor 6: Materials for language education and literacy. Education in the language is essential for language vitality. There are language communities that in spite of strong oral traditions do not wish their language to be written. In other communities, literacy is a source of pride. In general, however, literacy is directly linked with social and economic development. Books and materials are needed on all topics and for various age groups and language levels.

Table 5

Description of Material for Language Education and Literacy

\begin{tabular}{ll}
\hline Grade & Accessibility of written materials \\
\hline 5 & $\begin{array}{l}\text { There is an established orthography and literacy tradition with fiction and non-fiction and everyday media. The } \\
\text { language is used in administration and education. }\end{array}$ \\
& $\begin{array}{l}\text { Written materials exist and at school children are developing literacy in the language. The language is not used in } \\
\text { written form in the administration. }\end{array}$ \\
& $\begin{array}{l}\text { Written materials exist and children may be exposed to the written form at school. Literacy is not promoted through } \\
\text { print media. }\end{array}$ \\
Written materials exist but they may be useful only for some members of the community; for others, they may have \\
a symbolic significance. Literacy education in the language is not a part of the school curriculum. \\
A practical orthography is known to the community and some material is being written.
\end{tabular}

\section{Language Attitudes and Policies}

The maintenance, promotion, or abandonment of non-dominant languages may be dictated by the dominant linguistic culture, be it regional or national. The linguistic policies of a state may inspire linguistic minorities to mobilize their population towards the maintenance of their languages, or may force them to abandon them. These linguistic attitudes can be a powerful force both for promotion and loss of their languages.

Members of the dominant culture shape the ideological environment, often propagating a value system in which their own language is seen as a positive asset, and believed to be a unifying symbol for the region or state. When several larger linguistic communities compete for the same political or social space, they may each have their own conflicting linguistic attitudes. This leads to the general perception that a great variety of languages causes divisiveness and poses a threat to national unity. The fostering of a single dominant language 
is one attempt to deal with this real or merely perceived threat. In so doing, the governing body may legislate the use of language. Accordingly, the policies may discourage or even prohibit the use of other languages. National policy, including the lack of overt policy, has in any case a direct impact on the language attitude of the community itself.

Language attitude assessment. The two factors for assessing language attitudes and policies concerning both dominant and non-dominant languages are: (7) government and institutional language attitudes and policies, including official status and use; and (8) community members' attitudes towards their own language.

Factor 7: Governmental and institutional language attitudes and policies, including official status and use. A country may have an explicit policy for its great variety of languages. At one extreme, one language may be designated as the sole official language of the country, while all others are neglected. At the other extreme, all languages of a state may receive equal official status. Equal legal status, however, does not guarantee language maintenance or long-term vitality of a language. Official support of dominant and non-dominant languages may be ranked according to the following scale.

Equal support (5): All of a country's languages are valued as assets. All languages are protected by law, and the government encourages the maintenance of all languages by implementing explicit policies.

Differentiated support (4): Non-dominant languages are explicitly protected by the government but there are clear differences in the contexts in which the dominant/official languages(s) and non-dominant (protected) language(s) are used. The government encourages ethnolinguistic to maintain and use their languages, most often in private domains rather than in public domains. Some of the domain of non-dominant languages used to enjoy high prestige (for example ceremonial occasion).

Passive assimilation (3): The central authority is indifferent as to whether or not minority languages are spoken, as long as the dominant language is the language of interaction in public place. The dominant group's language is de facto the official language. The non-dominant languages do not enjoy high prestige.

Active assimilation (2): The government encourages minority groups to abandon their own languages by providing education for the minority group members in the dominant language only. Speaking and/or writing non-dominant languages are not encouraged.

Forced assimilation (1): The government has an explicit language policy supporting the dominant language while the non-dominant languages are neither recognized nor supported.

Prohibition (0): Minority languages are prohibited from use in any domain. Languages may be tolerated in private domains.

Table 6

Description of Government and Institutional Language Policies and Attitudes

\begin{tabular}{|c|c|c|}
\hline Degree of support & Grade & Official attitudes towards languages \\
\hline Equal support & 5 & All languages are protected. \\
\hline Differentiated support & 4 & $\begin{array}{l}\text { Non-dominant languages are protected primarily as the language of the private } \\
\text { domain. The use of the non-dominant languages is prestigious. }\end{array}$ \\
\hline Passive assimilation & 3 & $\begin{array}{l}\text { No explicit policy exists for minority languages; the dominant language prevails } \\
\text { in the public domain. }\end{array}$ \\
\hline Active assimilation & 2 & $\begin{array}{l}\text { Government encourages assimilation to the dominant language. There is no } \\
\text { protection for minority languages. }\end{array}$ \\
\hline Forced assimilation & 1 & $\begin{array}{l}\text { The dominant language is the sole official language, while non-dominant } \\
\text { languages are neither recognized nor protected. }\end{array}$ \\
\hline Prohibition & 0 & Minority languages are prohibited. \\
\hline
\end{tabular}


Factor 8: Community members' attitudes towards their own language. Members of a speech community are not usually neutral towards their own language. They may see it as essential to their community and identity and promote it; they may use it without promoting it; they may be ashamed of it and, therefore, not promote it; or they may see it as a nuisance and actively avoid using it.

When members' attitudes towards their language are very positive, the language may be seen as a key symbol of group identity. Just as people value family traditions, festivals, and community events, members of the community may see their language as a cultural core value, vital to their community and ethnic identity. If members view their language as a hindrance to economic mobility and integration into mainstream society, they may develop negative attitudes towards it. Attitudes of community members towards their own language may be assessed on the following scale (see Table 7).

Table 7

Description of Community Members Attitudes Towards Their Own Language

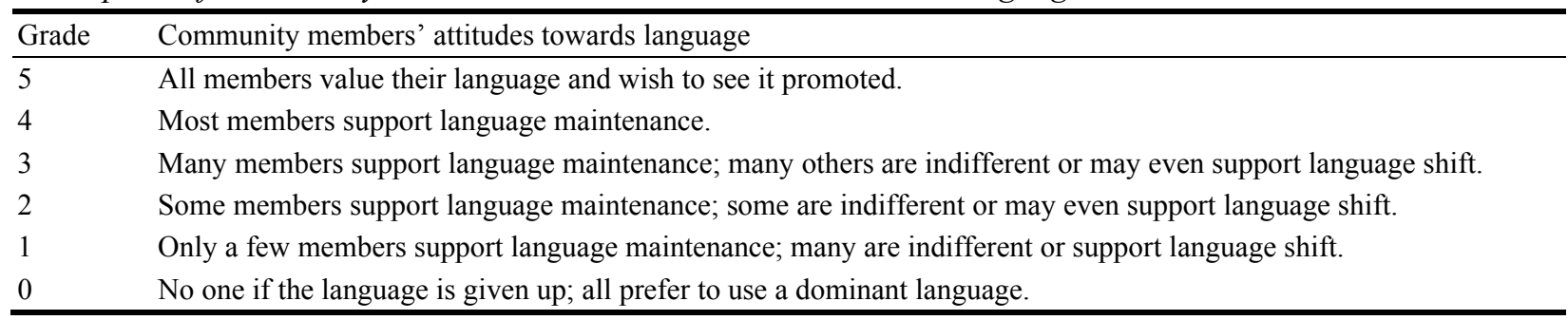

Language attitudes and policies: Interaction and social effects. Attitudes towards language, be they positive, indifferent, or negative, interact with government policy and societal pressure to result in increased or decreased language use in different domains.

In many cases, community members abandon their language because they believe they have no alternative, or because they do not have enough knowledge about the long-term consequences of the "choices" they make. People in such a situation have often been presented with either-or choice ("either you cling to your mother tongue and identify but don't get a job", or "you leave your language and have better chances in life"). In fact, maintaining and using both languages will allow even better chances in life.

When languages have an unequal power relationship, members of the non-dominant group usually speak both their native language and the dominant language, whereas the speakers of the dominant group are often monolingual. Speakers may gradually come to use only the dominant language. On the other hand, the subordinate group may resist linguistic domination and mobilize its members to revitalize or fortify their language. Strategies for such linguistic activism must be tailored to the particular socio-linguistic situation, which generally is one of the three types:

(1) Language Revival: reintroducing a language that has been in limited use for some time, such as Hebrew after the creation of the state of Israel, or Gaelic in Ireland;

(2) Language Fortification: increasing the presence of the non-dominant language to counter balance a perceived threat of a dominant language, such as Welsh;

(3) Language Maintenance: supporting the stable use, in speaking and in writing (where orthographies exist), of the non-dominant language in a region or state with both multilingualism and a dominant language (lingua franca), such as Maori in New Zealand.

For language vitality, speakers ideally not only strongly value their language, but they also know in which 
social domains their language is to be supported. A positive attitude is critical for the long term stability of a language.

\section{Documentation Urgency Assessment}

As a guide for assessing the urgency of documenting a language, the type and quality of existing language materials must be identified. This constitutes the final factor in the assessment of language endangerment (Factor 9: type and quality of documentation).

Of central importance are written texts, including transcribed and annotated audiovisual recording of natural speech. Such information is important in helping members of the language community to formulate specific tasks, and enables linguists to design research projects in collaboration with members of the language community.

Table 8

Description of the Amount and Quality of Documentation Found in the Language

\begin{tabular}{lll}
\hline Documentation & Grade & Language documentation \\
Superlative & 5 & $\begin{array}{l}\text { There are comprehensive grammar and dictionaries, extensive texts and a constant flow of language } \\
\text { material. Abundant annotated high-quality audio and video recording exist. } \\
\text { There is at least one good grammar, a few dictionaries, texts, literature, and everyday media; } \\
\text { adequate annotated high-quality audio and video recording. } \\
\text { There may be an adequate grammar, some dictionaries, and texts, but no everyday media; audio and } \\
\text { video recording may exist in varying quality or degree of annotation. } \\
\text { There are some grammatical sketches, wordlists, and texts useful for limited linguistic research but } \\
\text { with inadequate coverage. Audio and video recordings may exist in varying quality, with or without } \\
\text { any annotation. } \\
\text { Only a few grammatical sketches, short wordlists, and fragmentary texts exist. Audio and video } \\
\text { recording do not exist, are of unusable quality, or are completely unannotated. } \\
\text { No material exists. }\end{array}$ \\
Inadequate & 4 & 1
\end{tabular}

\section{Estimated Degrees of Endangerment in Ngwo, Majkuyə, Nweh, and Ngomba}

In the light of the factors discussed in the foregoing section, this section aims to discuss the nature and degree of language endangerment in the four languages under study.

\section{Intergenerational Language Transmission}

In the case of Ngwo, the children and parents who speak this language as their first language are mostly those resident in the village. As cited earlier they represent only about $12 \%$ of the total population of Ngwo indigenes. For those out of the village, only a very insignificant number of children speak Ngwo as their first language. From the findings such cases represent recent migrants, from the village. Many parents do not speak Ngwo with their children. Pidgin English is the home language. In fact, many of the children in the agricultural villages of the South West and some in the urban centers have creolized Pidgin English. The educated parents speak English at home as the first language with their children, the children later learn Pidgin English from their peers at school and in their various playgrounds and other interaction places such as the Church and the market. One could say that the population in the village, even though relatively small could guarantee perpetuation of the language. However, from this study it is realized that, the population in the village is very unstable. Many of those resident in the village would migrate to the urban centers if opportunities and availability of better facilities come up.

Many parents believe that speaking the dominant languages to their children exposes them to 
opportunities which Ngwo cannot provide. In the case of Mankon, whereby users of the indigenous language residing in the village now find themselves merged with the township population, present a more cumbersome situation. Many parents reported that they endeavor to communicate with their children in their indigenous language. Some of the children understand and respond in Pidgin English. Others who endeavor to speak code mix and code switch. They regret the fact that many of the children cannot carry out or sustain conversations fluently in the indigenous language. Some of the children feel that communicating in the indigenous language is primitive or signifying backwardness. The situation is even worse with those residing in other parts of the country.

In the case of Ngwe indigenes, it was discovered that parents and children resident in the village use the Nweh language as their first language. However, as in the case of Ngwo, many people in the village express the desire to migrate to the township for better opportunities. Many of the children outside the village do not use Nweh as their first language. The dominant language especially Pidgin English is used in the homes of the uneducated parents and English and sometimes French in the educated homes.

Ngomba speakers resident in Bamendjinda village where the study was limited, use Ngomba as their first language that is, parents and children alike. However, there is great infiltration of French in the home domains. Those out of the village endeavor to speak Ngomba to the children at home but sometimes there is great preference for French even at home.

\section{Absolute Number of Speakers}

The number of speakers for Ngwo, Maykuyə, Nweh, and Ngomba as cited earlier stands at 25,000; 200,000; 113,000; and 61,000 respectively.

Considering the population of indigenes from the respective villages which could be implied to be speakers of the various languages, one would say the languages are safe. However, this is not the actual situation. As indicated earlier, mostly those resident in the villages speak the language. In the case of Mankon indigenes as explained earlier, many of the children resident in the village are unwilling to speak the language almost like their counterparts resident outside the village. This leaves the language definitely endangered as the language is used mostly by the parental generation upward. It is worth noting that many of the migrant population into Mankon and Bamenda municipality have no need to learn the host language. On the contrary, the host uses the dominant languages to communicate with the immigrants. Nweh has the same situation with Ngwo and Mankon because the population resident in the village where the language is mostly spoken is insignificant compared to that outside. In the outside population, it is mostly the parent generation that speak Nweh and some of the parents and their children have creolized Pidgin English. Therefore, Nweh is also definitely endangered.

As for Ngomba, the Bamendjinda community in the village and outside do speak the language parent and children alike. However, there is the use of French alongside Ngomba. In the cities, French dominates but Ngomba is used as well. The situation of language use for Ngomba in Bamendjinda is unsafe meaning that the language is used by some children in all domains; it is used by all children in limited domains. From the foregoing, it is realized that these speech communities have many indigenes who do not speak their languages. There is also the situation of mixed marriages amongst parents of the different speech communities. In most of such cases, the dominant languages prevail in the homes. Summarily, there is the abandoning of the indigenous language for Pidgin English, English language, and French. 


\section{Proportion of Speakers Within the Total Population}

As indicated earlier, there are about 25,000 indigenes of Ngwo. Of that number only about 3,000 reside in the village and speak Ngwo. Of the 22,000 outside the village, only about 2,000 speak the language, mostly of the parent population. Therefore, just about 5,000 people out of 25,000 speak the language giving a total of $20 \%$. This shows that the language is severely endangered as only a minority speak the language.

As for Mankon, even though the indigenous population stands at about 200,000, many of the children in the village are abandoning the language. Many of those residing outside do not speak the language. The situation is worse in families where both parents are not from Mankon (cases of intermarriages). Some members of the parent generation residing outside Mankon do not speak the language. This makes the language definitely endangered. For Nweh, as cited earlier, most speakers are those residing in the village. For the indigenes living out of the village, the dominant languages are used alongside Nweh generally. The language is definitely endangered but a majority speak the language.

From this investigation, the Ngomba speakers in Bamendjida and out of the village speak the language alongside French. This study shows that it is unsafe. That is, nearly all speak the language.

\section{Shift in Domains}

Three of the four languages are characterized by dwindling domains. These languages include Mankon, Nweh, and Ngomba. As for Ngwo, it is characterized by a highly limited domain. Fluency in English and French is regarded as prestigious and moreover, constitutes official languages. Many educated Anglophone parents use English, while their francophone counterparts use French at home.

Pidgin English which is a lingua franca in the North West and South West regions features prominently in many of the domains for Ngwo, and enters in some of the domains for Nweh and Mankon speakers.

\section{Response to New Domains and Media}

The indigenous languages find no place in the public domain as they are not one of the official languages. None of them is used for administration or power. Therefore, the response of the language to new domains and media is very minimal and are coping in some domains.

\section{Materials for Language Education and Literacy}

Some written materials exist in all four languages, but they may only be useful for some members of the community; and for others they may have a symbolic significance. Literacy education in the language is not part of the school curriculum.

\section{Government and Institutional Language Attitudes and Policies}

No explicit policy exists for minority languages. The dominant languages prevail in the public domain.

\section{Community Members' Attitudes Towards Their Own Language}

In each of the four languages under study, some members support language maintenance, and many others are indifferent or may even support language loss.

\section{Amount and Quality of Documentation}

For Ngwo, only a few grammatical sketches, wordlists, and fragmentary text exist. Audio and video recordings do not exist. For Mankon, Nweh, and Ngomba, there may be an adequate grammar or sufficient amount of grammar dictionaries and texts but no everyday media; audio and video recording may exist in varying quality or degree of annotation. 


\section{Conclusion}

Tables 9-12 present a summary of each language.

Table 9

$N G W O$

\begin{tabular}{|c|c|c|c|c|}
\hline & Factors & Grade & Description & Description \\
\hline 1. & $\begin{array}{l}\text { Intergenerational transmission of } \\
\text { the language }\end{array}$ & 3 & Definitely endangered & $\begin{array}{l}\text { The language is used mostly by the parental generation } \\
\text { and upward. }\end{array}$ \\
\hline 2. & Absolute number of speakers & & & 25,000 \\
\hline 3. & $\begin{array}{l}\text { Proportion of speakers within the } \\
\text { total population }\end{array}$ & 2 & Severely endangered & A minority speak the language. \\
\hline 4. & Shift in domains of language use & 2 & Highly limited domains & $\begin{array}{l}\text { The language is used only in limited social domains } \\
\text { and for several functions. }\end{array}$ \\
\hline 5. & $\begin{array}{l}\text { Response to new domains and } \\
\text { media }\end{array}$ & 1 & Minimal & The language is used only in a few new domains. \\
\hline 6. & $\begin{array}{l}\text { Material for language and } \\
\text { educational literacy }\end{array}$ & 2 & & $\begin{array}{l}\text { Witten materials exist, but they may be only useful for } \\
\text { some members of the community and for others they } \\
\text { have a symbolic significance. Literacy education in the } \\
\text { language is not part of the school curriculum. }\end{array}$ \\
\hline 7. & $\begin{array}{l}\text { Government and institutional } \\
\text { language policies and attitudes }\end{array}$ & 3 & Passive assimilation & $\begin{array}{l}\text { No explicit policy exists for minority languages; the } \\
\text { dominant languages prevail in the public domain. }\end{array}$ \\
\hline 8. & $\begin{array}{l}\text { Community members attitudes } \\
\text { towards their own language }\end{array}$ & 2 & & $\begin{array}{l}\text { Some members support language maintenance. Some } \\
\text { are indifferent or may even support language shift. }\end{array}$ \\
\hline 9. & $\begin{array}{l}\text { Amount and quality of } \\
\text { documentation }\end{array}$ & 2 & Fragmentary & $\begin{array}{l}\text { There are some grammatical sketches, wordlists, and } \\
\text { texts useful for limited linguistic research but with } \\
\text { inadequate coverage. }\end{array}$ \\
\hline
\end{tabular}

Table 10

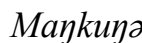

\begin{tabular}{|c|c|c|c|c|}
\hline & Factors & Grade & Description & Description \\
\hline 1. & $\begin{array}{l}\text { Intergenerational transmission of } \\
\text { the language }\end{array}$ & 3 & Definitely endangered & $\begin{array}{l}\text { The language is used mostly by the parental generation } \\
\text { and upward. }\end{array}$ \\
\hline 2. & Absolute number of speakers & & & 200,000 \\
\hline 3. & $\begin{array}{l}\text { Proportion of speakers within the } \\
\text { total population }\end{array}$ & 3 & Definitely endangered & A majority speak the language. \\
\hline 4. & Shift in domains of language use & 3 & Dwindling domains & $\begin{array}{l}\text { The ancestral language is used in home domains and } \\
\text { for many functions, but the dominant languages begin } \\
\text { to penetrate home domain. }\end{array}$ \\
\hline 5. & $\begin{array}{l}\text { Response to new domains and } \\
\text { media }\end{array}$ & 1 & Minimal & The language is used only in a few new domains. \\
\hline 6. & $\begin{array}{l}\text { Material for language and } \\
\text { Educational literacy }\end{array}$ & 2 & & $\begin{array}{l}\text { Written materials exist, but they may be only useful } \\
\text { for some members of the community and for others } \\
\text { they have a symbolic significance. Literacy education } \\
\text { in the language is not part of the school curriculum. }\end{array}$ \\
\hline 7. & $\begin{array}{l}\text { Government and institutional } \\
\text { language policies and attitudes }\end{array}$ & 3 & Passive assimilation & $\begin{array}{l}\text { No explicit policy exists for minority languages; the } \\
\text { dominant languages prevail in the public domain. }\end{array}$ \\
\hline 8. & $\begin{array}{l}\text { Community members attitudes } \\
\text { towards their own language }\end{array}$ & 2 & & $\begin{array}{l}\text { Some members support language maintenance. Some } \\
\text { are indifferent or may even support language shift. }\end{array}$ \\
\hline 9. & $\begin{array}{l}\text { Amount and quality of } \\
\text { documentation }\end{array}$ & 3 & Fair & $\begin{array}{l}\text { There may be an adequate grammar or sufficient } \\
\text { amount of grammars, dictionaries, and texts, but no } \\
\text { everyday media; audio and video recordings may exist } \\
\text { in varying quality or degree of annotation. }\end{array}$ \\
\hline
\end{tabular}


Table 11

NGWE

\begin{tabular}{|l|l|l|l|l|}
\hline & Factors & Grade & Description & Description \\
\hline 1. & $\begin{array}{l}\text { Intergenerational transmission of } \\
\text { the language }\end{array}$ & 3 & Definitely endangered & $\begin{array}{l}\text { The language is used mostly by the parental generation } \\
\text { and upward. }\end{array}$ \\
\hline 2. & Absolute number of speakers & & & 113,000 \\
\hline 3. & $\begin{array}{l}\text { Proportion of speakers within the } \\
\text { total population }\end{array}$ & 3 & Definitely endangered & A majority speak the language. \\
\hline 4. & Shift in domains of language use & 3 & Dwindling domain & $\begin{array}{l}\text { The ancestral language is used for home domains and } \\
\text { for many functions, but the dominant languages begin } \\
\text { to penetrate home domains. }\end{array}$ \\
\hline 5. & $\begin{array}{l}\text { Response to new domains and } \\
\text { media }\end{array}$ & 1 & Minimal & The language is used only in a few new domains. \\
\hline 6. & $\begin{array}{l}\text { Material for language and } \\
\text { Educational literacy }\end{array}$ & 2 & & $\begin{array}{l}\text { Written materials exist, but they may be only useful } \\
\text { for some members of the community and for others } \\
\text { they have a symbolic significance. Literacy education } \\
\text { in the language is not part of the school curriculum. }\end{array}$ \\
\hline 7. & $\begin{array}{l}\text { Government and institutional } \\
\text { language policies and attitudes }\end{array}$ & 3 & Passive assimilation & $\begin{array}{l}\text { No explicit policy exists for minority languages; the } \\
\text { dominant languages prevail in the public domain. }\end{array}$ \\
\hline 8. & $\begin{array}{l}\text { Community members attitudes } \\
\text { towards their own language }\end{array}$ & 2 & $\begin{array}{l}\text { Some members support language maintenance. Some } \\
\text { are indifferent or may even support language shift. }\end{array}$ \\
\hline 9. & $\begin{array}{l}\text { Amount and quality of } \\
\text { documentation }\end{array}$ & $\begin{array}{l}\text { There may be an adequate grammar or sufficient } \\
\text { amount of grammars, dictionaries, and texts, but no } \\
\text { everyday media; audio and video recordings may exist } \\
\text { in varying quality or degree of annotation. }\end{array}$ \\
\hline
\end{tabular}

Table 12

$N G O M B A$

\begin{tabular}{|c|c|c|c|c|}
\hline & Factors & Grade & Description & Description \\
\hline 1. & $\begin{array}{l}\text { Intergenerational } \\
\text { transmission of the language }\end{array}$ & 5 & Safe & The language is used by all ages from children up. \\
\hline 2. & Absolute number of speakers & & & $\begin{array}{l}61,000 \text { speakers, the number of monolingual speakers } \\
\text { is not known }\end{array}$ \\
\hline 3. & $\begin{array}{l}\text { Proportion of speakers within the } \\
\text { total population }\end{array}$ & 4 & Unsafe & Nearly all speak the language. \\
\hline 4. & Loss of existing domains & 3 & Dwindling & $\begin{array}{l}\text { The language is in home domains and for many } \\
\text { functions, but the dominant language begins to } \\
\text { penetrate even home domains. }\end{array}$ \\
\hline 5. & $\begin{array}{l}\text { Response to new domains and } \\
\text { media }\end{array}$ & 1 & Minimal & The language is used only in a few new domains. \\
\hline 6. & $\begin{array}{l}\text { Material for language education } \\
\text { and literacy }\end{array}$ & 2 & & $\begin{array}{l}\text { Written materials exist, but they may only be useful } \\
\text { for some members of the community; and for others, } \\
\text { they may have a symbolic significance. Literacy } \\
\text { education in the language is not a part of the school } \\
\text { curriculum. }\end{array}$ \\
\hline 7. & $\begin{array}{l}\text { Government and institutional } \\
\text { language policies and attitude }\end{array}$ & 3 & Passive assimilation & $\begin{array}{l}\text { No explicit policy exists for minority language } \\
\text { prevails in the public domain. }\end{array}$ \\
\hline 8. & $\begin{array}{l}\text { Community members attitudes } \\
\text { towards their own language }\end{array}$ & 3 & & $\begin{array}{l}\text { Many members support language maintenance; others } \\
\text { are indifferent or may even support language loss. }\end{array}$ \\
\hline 9. & $\begin{array}{l}\text { Amount and quality of } \\
\text { documentation }\end{array}$ & 3 & Fair & $\begin{array}{l}\text { There may be an adequate grammar or sufficient } \\
\text { amount of grammars, dictionaries, and texts, but no } \\
\text { everyday media; audio and video recordings may exist } \\
\text { in varying quality or degree of annotated. }\end{array}$ \\
\hline
\end{tabular}

As can be seen from this study, the most critical factors are those related to attitudes and material development for all the languages studied. There are intergenerational language transmission and negative attitudes problems for Ngwo, Mankon, and Nweh languages. These problems are worst for the Ngwo language. 
For some years now, there have been various attempts at revitalisation of the languages. For now, a great deal of work is going on the translation of the Bible into the various languages by organizations like Cameroon Association for Bible Translation and Literacy (CABTAL) and Summer Institute of Linguistics (SIL).

Despite all these efforts to revitalize these languages, the following questions remain: Who will read the text? How long will the texts be useful to the population? Are the people really concerned with the maintenance of their languages? If not, how can the community members' attitude towards their language be reversed to improve on intergenerational transmission of the languages? To this effect, there is an examination of some general objectives for the Revitalization of Endangered Languages. These include the following possibilities:

(1) Instil in children the need to know their mother tongue. To this effect it will be important to find strategies to motivate parents to speak their mother tongue to their children, since they are the main agents of language transmission. Moreover, it will be important to arouse in children, the need to learn their mother tongue as well as to sensitize them on the importance bilingualism and the need for good bilinguals to keep their languages apart.

(2) Value the elements of the mother tongue culture in the eyes of the children and the speakers so that the community should understand that it is worth revaluating their languages. This will consist in creating games that children can play. It will also entail encouraging everyone especially children to attend and participate in the end of year village festivals like those of 2012 and 2014 cited earlier.

(3) Instil parents to read information in mother tongue. Also the habits to read mother tongue documents should not be limited to literacy materials.

(4) Cause parents to be proud of their language and their culture so that they get motivated to speak it with their children. This will go a long way to ensure intergenerational transmission of the mother tongue.

(5) Instil parents to transmit information via the mother tongue, whether orally or written.

(6) Arouse interest for mother tongue among parents, through the use of new technologies of information and communication, which offer opportunities to parents to listen to radio and TV programs and the use of the computer in the mother tongue.

(7) Government should look at the possibility of introducing mother tongue education in the school curricula most especially, to consider early education in the indigenous languages. This has begun in some of the Cameroonian languages and is highly applauded but there is need to extend to more. The introduction of the study of Cameroonian Languages in some of the colleges of education will also go a long way to ameliorate the situation.

\section{References}

Angwafor, A. (2010). Royalty and politics: The story of my life. Bamenda: Langa'a Publishing CIG.

Atenchong, N. T. (2012). An optimality analysis of aspects of the phonology of Ngwe (Unpublished master's thesis). University of Dschang, Dschang, Cameroon.

Bitjaa Kody, Z. D. (2005, July). Vers un instrument de mesure de la dynamique des petites langues (An instrument for measuring the dynamics of small languages). Paper presented at the workshop on assessing langue endangerment at Nacalco, Yaounde, Cameroon.

Breton, R., \& Bikia, E. (1991). Atlas Linguistic du Cameroun (The linguistic atlas of Cameroon, ALCAM).

Crystal, D. (2000). Language death. Cambridge: Cambridge University Press.

Evans, N. (2010). Endangered languages and what they have to tell us. Oxford: Wiley Blackwell.

Fishman, J. A. (1991). Reversing language shift: Theoretical and empirical foundations of assistance to threatened languages. Clevedon, Bristol City: Multilingual Matters. 
Grimes, B. F. (2000). Ethonlogue: The languages of the world (14th ed.). Dallas/Texas: Summer Institute of Linguistics.

Landweer, D. (2000). Indicators of ethnolinguistic vitality. London: Longmans Publication, Britain.

Mufwene, S. S. (1998). Language endangerment: What have pride and prestige got to do with it? Retrieved from http:/humanities.uchicago.edu/humanities/linguistics/faculty/mufw_enda.html

Nettle, D., \& Romaine, S. (2000). Dying words the extinction of the world's languages. Oxford: Oxford University Press.

NgouoTchio, H. R. (2008). An evaluation of the ethnolinguistic vitality of the Ngomba language in the Bamboutos division in the west province of Cameroon (Unpublished master's thesis). University of Dschang, Dschang Cameroon.

Ngwo Cultural and Development Association (NCUDA). (2014). The Ngwo blue print. Bamenda: Unique Printers.

Njwe, E. N. (2005). Tone analysis of Ngwo (Unpublished doctoral dissertation). University of Ibadan, Ibadan, Nigeria.

Trudgill, P. (1991). Language maintenance and language shift: Preservation versus extinction. International Journal of Applied Linguistics, 1(1), 61-69.

Turin, M. (2007). Linguistic diversity and the preservation of endangered languages: A case study from Nepal. Kathmandu: ICIMOD.

UNESCO ad hoc expert group on endangered languages. (2003). Language vitality and endangerment. Retrieved from www.unesco.org

UNESCO. (2002). Universal declaration on cultural diversity, cultural diversity series. Retrieved from www.unesdoc.unesco.org

UNESCO.org. (2009). Retrieved from http://www.unesco.org/culture/ich/index.php?pg=00139 